\title{
Noninvasive prenatal testing for chromosome aneuploidies and subchromosomal microdeletions/ microduplications in a cohort of 8141 single pregnancies
}

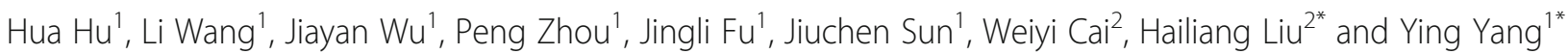

\begin{abstract}
Background: Noninvasive prenatal testing (NIPT) for fetal aneuploidies by scanning cell-free fetal DNA in maternal plasma is rapidly becoming a first-tier aneuploidy screening test in clinical practices. With the development of whole-genome sequencing technology, small subchromosomal deletions and duplications that could not be detected by conventional karyotyping are now able to be detected with NIPT technology.

Methods: In the present study, we examined 8141 single pregnancies with NIPT to calculate the positive predictive values of each of the chromosome aneuploidies and the subchromosomal microdeletions and microduplications.

Results: We confirmed that the positive predictive values (PPV) for trisomy 13, trisomy 18, trisomy 21, and sex chromosome aneuploidy were $14.28 \%, 60 \%, 80 \%$, and $45.83 \%$, respectively. At the same time, we also found $51(0.63 \%)$ positive cases for chromosomal microdeletions or microduplications but only 13 (36.11\%) true-positive cases. These results indicate that NIPT for trisomy 21 detection had the highest accuracy, while accuracy was low for chromosomal microdeletion and microduplications.
\end{abstract}

Conclusions: Therefore, it is very important to improve the specificity, accuracy, and sensitivity of NIPT technology for the detection of subchromosomal microdeletions and microduplications.

Keywords: Noninvasive prenatal testing (NIPT), Chromosome aneuploidies, Sex chromosome aneuploidy, Subchromosomal microdeletions/microduplications

\section{Introduction}

In 1997, Lo et al. reported that plasma from pregnant women carrying male fetuses contained cell-free DNA (cf-DNA) derived from the Y-chromosome [1]. Then, cell-free fetal DNA (cff-DNA) was subsequently reported to be used to detect fetal Down's syndrome and additional fetal aneuploidies in clinical practice [2-4]. Now, noninvasive prenatal testing (NIPT) for fetal aneuploidies by scanning cell-free fetal DNA in maternal plasma is rapidly becoming a first-tier aneuploidy screening test in clinical

\footnotetext{
* Correspondence: hlliu@capitalbiotech.com; yy630917@126.com

${ }^{2}$ CapitalBio Technology Inc., Beijing 101111, China

${ }^{1}$ Second Affiliated Hospital, Army Military Medical University, Chongqing 400037, China
}

practice $[5,6]$. An increasing number of clinical studies suggest that NIPT has a high sensitivity and specificity for screening trisomies 21 (T21), 18, and 13. Several recent studies have shown that the PPV range of T21 was $65-94 \%$, T18 was $47-85 \%$, and T13 was $12-62 \%$ [7-9].

Large or small subchromosomal deletions and duplications are always associated with genetic disorders and syndromes; these are derived from genomic structural changes, such as copy number variants, resulting from abnormal gene dosage with a dramatic influence on gene expression level and phenotype [10]. Currently, the prenatal diagnosis of large subchromosomal deletions and duplications in clinical practice still relies on invasive testing, such as fetal genetic material, through chorionic 
villus sampling (CVS) and amniocentesis using karyotyping. With the development of whole-genome sequencing technology, smaller pathogenic genomic rearrangements that could not be detected by conventional karyotyping are now able to be detected. Despite the fact that an increasing number of studies have been conducted on the clinical application of NIPT for chromosome aneuploidy detection, knowledge about microdeletion and microduplication syndromes (MMSs) detection has not been given early attention during pregnancy [11]. However, the incidence and severity of the microdeletion and microduplication are higher for Edwards (trisomy 18) and Patau (trisomy 13) syndromes than the 22q11.2 deletion syndrome (known as DiGeorge Syndrome (DGS)), with an incidence of 1 in 992 pregnancies in the low-risk population [12-14]. Therefore, NIPT on subchromosomal microdeletions and microduplications is important for chromosome aneuploidies. This could help identify high-risk pregnancies and offer the possibility of a confirmatory invasive diagnostic test after counseling to offer better clinical management during pregnancy and after birth, where early intervention can potentially improve the quality of life of the newborn.

In the present study, we examined 8152 single pregnancies undergoing NIPT, both for detecting common chromosome aneuploidies, including trisomy 13, 18, and 21 and sex chromosomes, as well as subchromosomal microdeletions/microduplications.

\section{Materials and methods \\ Patients}

From March 2016 to May 2017, 8152 pregnant women (Second Affiliated Hospital, Army Military Medical University) opted for NIPT to avoid fetal T13, T18, and T21 aneuploidies. Informed written consent was obtained from all pregnant women who agreed to receive NIPT. Pregnancies with high risks were divided into advanced maternal age, ultrasound abnormalities, poor fertility history, positive serum screening, and other groups.

\section{Samples preparation and sequencing}

Whole blood samples of 5 to $10 \mathrm{~mL}$ from pregnant women were collected in EDTA within $8 \mathrm{~h}$ or cell-free DNA was collected in BCT tubes (Streck Inc.; Omaha, $\mathrm{NE}$ ) within $72 \mathrm{~h}$ at $4{ }^{\circ} \mathrm{C}$. Afterwards, cfDNA extraction, library construction, quality control, and pooling were performed according to the JingXin Fetal Chromosome Aneuploidy (T21, T18, T13) Testing Kits (CFDA registration permit No. 0153400300). Following the DNA sequencing, 15 20 libraries were pooled and sequenced within $\sim 200$ bp reads using the JingXin BioelectronSeq 4000 System (CFDA registration permit NO. 20153400309), which is a type of semiconductor sequencer. Sequencing reads were filtered and aligned to the human reference genome (hg19). Fetal DNA concentration was calculated as a quality control using our previously described method [15]. Samples failing the quality criteria of cfDNA extraction, library construction, and sequencing as well as fetal DNA concentration $(<4 \%)$ were kicked out.

\section{Statistics and analysis}

Combined GC correction and Z-score testing methods were used to identify fetal autosomal aneuploidies, as described previously [16]. Meanwhile, fetal and maternal chromosome copy number variations $(\mathrm{CNVs})$ were classified with our modified Stouffer's Z-score method as described previously [15]. In a previous study, a cutoff value of $Z$-score $>3$ was used to determine whether the ratio of the chromosomes was increased and if fetal trisomies 21, 18 , and 13 were also present. Here, each chromosome with an absolute value of the $Z$-score greater than 3 was marked with chromosome aneuploidies or microdeletions/ microduplications.

\section{Chromosome karyotype analysis}

Chromosome karyotype analysis under sterile conditions was performed on fetal DNA, on cultured amniocytes, and on lymphocytes according to standard protocols. The amniocentesis was performed with the guidance of ultrasound and was centrifuged, inoculated in culture medium, and cultured at $37^{\circ} \mathrm{C}$. Once many circular translucent dividing cells had emerged, colchicine was added and cultured for another $3 \mathrm{~h}$. When the number of circular translucent cells increased, cells were harvested for chromosome preparation. Subsequently, 3 $\mathrm{mL}$ of the parents' peripheral blood was collected with heparin anticoagulation and inoculated in phytohemagglutinin (PHA) culture medium for further karyotype analysis. According to the principle of "An International System for Human Cytogenetic Nomenclature, ISCN2013", a total of 60 dividing phases were counted using an AI chromosome image analysis system (CytoVision, Switzerland), and 20 karyotypes were analyzed and repeated three times.

\section{Fish}

Fluorescence in situ hybridization (FISH) was used to analyze the interchromosomal rearrangement of the proband. The slides were immersed in Citrisolve for $15 \mathrm{~min}$, jet air-dried, immersed in Lugol solution for $5 \mathrm{~min}$, and immersed in $2.5 \%$ sodium thiocyanate for $30 \mathrm{~s}$. The slides were then placed in 10-mM citrate/citric acid solution ( $\mathrm{pH}$ 6.0) and microwaved on a high setting for $5 \mathrm{~min}$ followed by 15 to $45 \mathrm{~min}$ in $0.4 \%$ pepsin solution (pepsin $\mathrm{A} / 0.9 \%$ sodium chloride at $\mathrm{pH} 1.5$ ) at $37^{\circ} \mathrm{C}$. Ten microliters of FISH reagent (7- $\mu \mathrm{L}$ LSI buffer and $3 \mu \mathrm{L}$ probe) were placed on each slide, and a cover-slip was added. Slides were then denatured in a Hybrite set at a melting temperature of $80^{\circ} \mathrm{C}$ for $5 \mathrm{~min}$ and were 
incubated in a humidified chamber at $37^{\circ} \mathrm{C}$ for $12 \mathrm{~h}$. The slides were then washed in $2 \times \mathrm{SSC} / 0.1 \% \mathrm{NP} 40$ at $70^{\circ} \mathrm{C}$ for $2 \mathrm{~min}$ and counterstained with 4 , 6 -diamidino-2-phenylindole dihydrochloride. The cells were analyzed by a microscopist (ML) using a fluorescence microscope equipped with the appropriate filter sets. A minimum of 50 cells and a maximum of 200 cells were scored per case. A minimum of 20 abnormal cells was required for a sample to be considered abnormal $[17,18]$.

\section{Results}

Among the 8152 cases undergoing NIPT, we found that due to the low concentration of fetal DNA, 11 cases were not eligible for the next analysis, so the remaining 8141 cases were under-analyzed in the present study. Based on these results, the maternal age for the 8141 pregnancies ranged from 15 to 46 years old. The group aged 25 to 29 years old was the majority (3328, 40.88\%) group. Pregnant women older than 35 years were $13.79 \%$. The gestational age at blood sampling ranged from 9 to 34 weeks, and $53.36 \%$ of the group had a gestational age from 13 to 16 weeks (see Table 1 ). The positive rate increased with maternal age and the number of the positive cases in four age groups, as shown in Fig. 1. Binomial test were used to test associations between positive and negative cases in four age groups according to the single pregnancies, and the differences were significant $\left(\operatorname{mean}_{\leq 24} \pm \mathrm{SD}_{\leq 24}=1.9833\right.$ $+0.1281, p<0.05 ;$ mean $_{25-29} \pm \mathrm{SD}_{25-29}=1.9867+0.11475$, $p<0.05 ; \quad$ mean $_{30-34} \pm \mathrm{SD}_{30-34}=1.9836+0.1271, \quad p<0.05$; mean $\left._{\geq 35} \pm \mathrm{SD}_{\geq 35}=1.9757+0.15413, p<0.05\right)$. Weekly time

Table 1 Maternal characteristics and gestational age of blood sampling

\begin{tabular}{lll}
\hline Maternal age at NIPT (years) & Number & Percent (100\%) \\
\hline$\leq 24$ & 1533 & 18.83 \\
$25-29$ & 3328 & 40.88 \\
$30-34$ & 2157 & 26.50 \\
$35-40$ & 1011 & 12.42 \\
$\geq 41$ & 112 & 1.38 \\
Advanced maternal age ( $\geq 35$ years old) & 1123 & 13.79 \\
Gestational age at NIPT (weeks) & & \\
$\leq 8$ & 0 & 0.00 \\
$9-12$ & 916 & 11.25 \\
$13-16$ & 4344 & 53.36 \\
$17-20$ & 1509 & 18.54 \\
$21-24$ & 810 & 9.95 \\
$25-28$ & 347 & 4.26 \\
$\geq 29$ & 212 & 2.60 \\
Unknown & 3 & 0.04 \\
Range (weeks) & $9-34$ & $/$ \\
\hline
\end{tabular}

/no data points of gestation aged from 12 to 26 weeks were tested, but no significant differences were found. In addition to that basic information, we also counted the clinical reasons for NIPT, finding that $13.79 \%$ of the group had advanced maternal age more than 35 years (included), and 26 pregnancy cases had ultrasound abnormalities. Other reasons included poor fertility and high risk in serum biochemistry screening.

As shown in Fig. 2, we used linear regression analysis to find the relationship between fetal DNA concentration and $Z$ value in the positive cases. We found that there was no obvious linear relationship between them except in true-positive cases with fetal DNA concentration $(r=0.128$, $\mathrm{df}=33, p=0.02)$. There were $88(1.08 \%)$ positive cases for common chromosome and sex chromosome aneuploidies (SCAs) detection, including 11 cases of trisomy 13, 7 cases of trisomy 18, 36 cases of trisomy 21, and 34 cases of sex chromosome aneuploidy (Table 2). Among them, there were 35 (57.38\%) true-positive cases, 26 (42.62\%) false-positive cases, and 27 unverified cases that chose to continue gestation or to terminate the pregnancy. For the 35 true-positive cases, there were 20 cases for T21, 1 case for T13, 3 cases for T18, and 11 cases for sex chromosome abnormalities. A total of 26 false-positive cases were normal. Among the 20 cases of T21, two T21 cases were verified as $46, \mathrm{XY}, \operatorname{rob}(14,21)(\mathrm{q} 10 ; \mathrm{q} 10),+21$ by amniotic fluid karyotyping analysis.

In addition, we calculated positive cases of chromosomal microdeletions or microduplications as well. Overall, we found $51(0.63 \%)$ cases for chromosomal microdeletions or microduplications, with 13 (36.11\%) true-positive cases, 23 (63.89\%) false-positive cases, and 15 unverified cases. Of these 23 cases with false positives, the NIPT result of one case showed chromosome 15 microdeletion; however, the amniotic fluid karyotyping analysis prompted 46,XX, 1qh+; the rest were proven normal. Among the 13 cases with true positives, 9 cases occurred because of genetic mutations, while 4 cases were inherited from parents. The karyotypes were confirmed by amniotic fluid karyotyping analysis and FISH (Table 3).

\section{Discussion}

Noninvasive prenatal testing of cell-free DNA in maternal plasma, which is a mixture of maternal DNA and a low percentage of fetal DNA, revolutionized the approach to prenatal fetal aneuploidies screening using massively parallel sequencing [19]. A large number of validation studies reporting the sensitivity and specificity of NIPT have been published [3, 20]. Recently, NIPT was also introduced to subchromosomal copy number variations (CNVs), typically less than $5 \mathrm{Mb}$ in size, that could either be inherited from parents with or without symptoms or occur de novo $[19,21]$. With the 


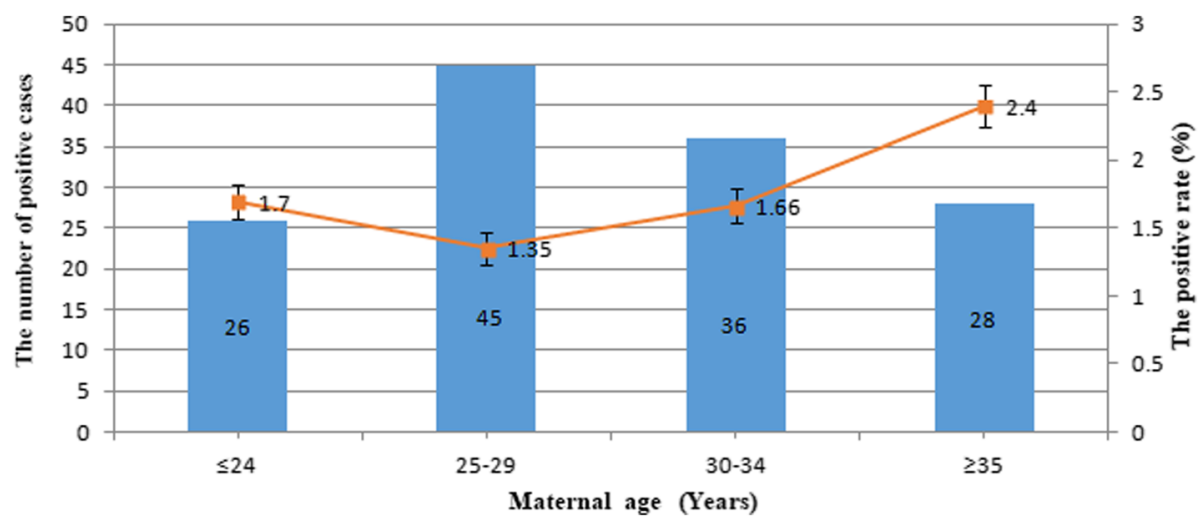

Fig. 1 The positive rate of NIPT for aneuploidy and CNV increases with maternal age and the number of positive cases in the four age groups. Binomial test were used to test associations between positive and negative cases in four age groups according to the single pregnancies and the differences were significant (mean $\leq 24 \pm \mathrm{SD}_{\leq 24}=1.9833+0.1281, p<0.05 ;$ mean $_{25-29} \pm \mathrm{SD}_{25-29}=1.9867+0.11475, p<0.05 ;$ mean $_{30-34} \pm \mathrm{SD}_{30-34}=$ $1.9836+0.1271, p<0.05 ;$ mean $\left._{235} \pm \mathrm{SD}_{\geq 35}=1.9757+0.15413, p<0.05\right)$
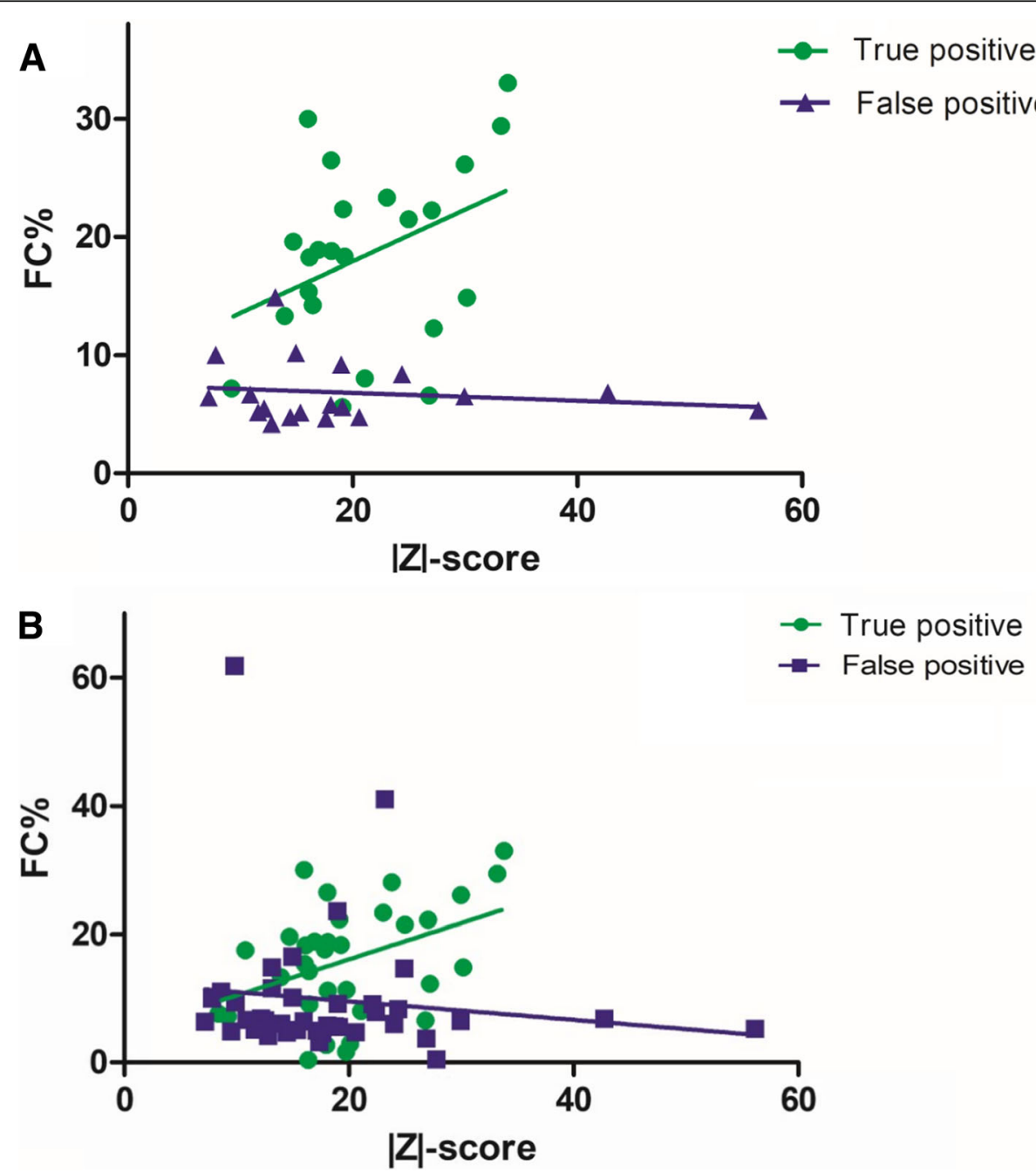

Fig. 2 The relationship between fetal DNA concentration and $Z$ value in true-positive cases. a True positive group of the trisomy sample $(r=0.102, \mathrm{df}=21$, $p=0.076)$, false positive group of the trisomy sample $(r=-0.035, \mathrm{df}=17, p=0.537)$. $\mathbf{b}$ True positive group of the total sample $(r=0.128, \mathrm{df}=33, p=0.02)$, false positive group of the total sample $(r=-0.003, \mathrm{df}=55, p=0.361)$ 
Table 2 NIPT results for chromosome aneuploid and microdeletions/microduplications validated by fetal karyotyping analyses or FISH

\begin{tabular}{|c|c|c|c|c|c|c|c|c|}
\hline \multirow{2}{*}{$\begin{array}{l}\text { No. of } \\
\text { chromosome }\end{array}$} & \multicolumn{4}{|l|}{ Aneuploid } & \multicolumn{4}{|c|}{ Microdeletions and microduplications } \\
\hline & $\begin{array}{l}\text { Positive } \\
\text { cases }\end{array}$ & $\begin{array}{l}\text { True-positive } \\
\text { cases }\end{array}$ & $\begin{array}{l}\text { False-positive } \\
\text { cases }\end{array}$ & Unverified & $\begin{array}{l}\text { Positive } \\
\text { cases }\end{array}$ & $\begin{array}{l}\text { True-positive } \\
\text { cases }\end{array}$ & $\begin{array}{l}\text { False-positive } \\
\text { cases }\end{array}$ & Unverified \\
\hline Chr1 & / & / & / & / & 1 & 0 & 0 & 1 \\
\hline Chr2 & / & / & / & / & 1 & 1 & 0 & 0 \\
\hline Chr3 & / & / & / & / & 2 & 0 & 1 & 1 \\
\hline Chr4 & / & / & / & / & 3 & 1 & 1 & 1 \\
\hline Chr6 & / & / & / & / & 1 & 1 & 0 & 0 \\
\hline Chr7 & / & / & / & / & 4 & 1 & 2 & 1 \\
\hline Chr8 & / & I & / & / & 10 & 1 & 8 & 1 \\
\hline Chr9 & / & / & / & / & 1 & 0 & 1 & 0 \\
\hline Chr10 & / & / & / & / & 1 & 1 & 0 & 0 \\
\hline Chr13 & 11 & $1(14.28 \%)$ & $6(85.71 \%)$ & 4 & 1 & / & / & 1 \\
\hline Chr14 & / & / & / & / & 2 & 1 & 1 & 0 \\
\hline Chr15 & / & / & / & / & 4 & 1 & 3 & 0 \\
\hline Chr16 & / & / & / & / & 2 & 0 & 2 & 0 \\
\hline Chr18 & 7 & $3(60 \%)$ & $2(40 \%)$ & 2 & 6 & 1 & 0 & 5 \\
\hline Chr20 & / & / & / & / & 3 & 0 & 2 & 1 \\
\hline Chr21 & 36 & 20 (80\%) & 5 (20\%) & 11 & 3 & 2 & 1 & 0 \\
\hline Chr22 & / & / & / & / & 2 & 1 & 1 & 0 \\
\hline$X$ or $Y$ & 34 & 11 (45.83\%) & $13(54.17 \%)$ & 10 & 4 & 1 & 0 & 3 \\
\hline Total & 88 (1.08\%) & 35 (57.38\%) & 26 (42.62\%) & 27 & $51(0.63 \%)$ & 13 (36.11\%) & 23 (63.89\%) & 15 \\
\hline
\end{tabular}

/ no data

widespread use of whole genome analysis technology, an increasing number of microdeletion and microduplication syndromes connected to certain phenotypes have been diagnosed and researched [22, 23]. In general, microdeletions occurred more frequently than microduplications [7].

In this study, we are the first to use NIPT to screen a large population in the Chongqing area. This NIPT technology uses a semiconductor sequencing platform (SSP) to reliably detect subchromosomal deletions/duplications in women carrying high-risk fetuses. Here, we reviewed the use of NIPT in the context of screening for common chromosome aneuploidies as well as subchromosomal microdeletions and microduplications within a cohort of 8141 single pregnancies (with 11 unqualified samples ruled out) using 4.89 million reads. From our results, we learned that the maternal age for 8141 pregnancies ranged from 15 to 46 years. The group aged 25 to 29 years made up the majority $(3328,40.88 \%)$ of the group. Pregnant women over 35 years old were $13.79 \%$ of the group. The gestational age at blood sampling ranged from 9 to 34 weeks, and $53.36 \%$ of the group had a gestational age from 13 to 16 weeks.

There were a total of $88(1.08 \%)$ positive cases for common chromosome and sex chromosome aneuploidies
(SCAs) detected, including 11 cases of trisomy 13, 7 cases of trisomy 18, 36 cases of trisomy 21, and 34 cases of sex chromosome aneuploidies. The positive predictive value (PPV) for common chromosomal aneuploidies in our present study was $57.38 \%$, and for T21, T18, and T13, the PPV was $80 \%, 60 \%$, and $14.28 \%$, respectively. In several recent studies, the PPV range of T21 was $65-94 \%$, the PPV range of T18 was $47-85 \%$, and the PPV range of T13 was $12-62 \%[8,9,24]$. Our results fall within this range. Interestingly, the PPV for SCAs was $45.83 \%$, obviously higher than that of T18 and T13. In this study, the true-positive rate of $\mathrm{T} 13$ is relatively low, which may be related to the size of chromosome 13 or the GC ratio on chromosome 13. Zhang et al. showed that such a test was less successful for detecting trisomy 18 and trisomy 13 compared with trisomy 21 [3]. The mixed results may be related to the GC bias caused by sample preparation or sequencing procedures. The differences in the inherent $\mathrm{GC}$ content of the chromosomes combined with the sequencer-related GC bias explained the significant correlation between the read coverage and the corresponding $\mathrm{GC}$ content. For example, chromosome 13 had a relatively low GC content, and the PCR and sequencing process enriched chromosomes with a higher GC content, leading to a relatively low read coverage for chromosome 13 and 
Table 3 The true-positive cases of microdeletions/microduplications results

\begin{tabular}{|c|c|c|c|c|}
\hline Case & NIPT result CNV location (M) or Z-score & CVS & FISH & Pathogenicity \\
\hline $\begin{array}{l}\text { Case } \\
1\end{array}$ & $2 z=17.503$ & $46, X Y$ & $47, \mathrm{XN}+2[15] / 46, \mathrm{XN}[85]$ & / \\
\hline $\begin{array}{l}\text { Case } \\
2\end{array}$ & $\begin{array}{l}\text { 4p16.3-12(dup:0.1Mb-48Mb);8p23.3- } \\
\text { 23.2(del:1-4Mb) }\end{array}$ & $46, X X$, der(8)t(4;8)(p12;p23)pat & / & $\begin{array}{l}\text { Wolf-Hirschhorn syndrome } \\
\text { [35] }\end{array}$ \\
\hline $\begin{array}{l}\text { Case } \\
3\end{array}$ & $\begin{array}{l}\text { 6q26-q27(dup:143 Mb-158Mb);6q25.3- } \\
\text { 27(del:162Mb-171Mb) }\end{array}$ & $46, \mathrm{XN}$,del(6)(q26) & $46, \mathrm{XN}$,del(6) & Leigh-like syndrome [36] \\
\hline $\begin{array}{l}\text { Case } \\
4\end{array}$ & $7_{z}=28.110$ & $46, X Y$ & $7 q 31.1(110.82 \mathrm{Mb}-111.12 \mathrm{Mb}) \times 1$ & NA \\
\hline $\begin{array}{l}\text { Case } \\
5\end{array}$ & 8p23.1-11(dup:2Mb-37Mb) & $46, X N$,der(15)t(8;15)(p11.2;p12)pat & / & $\begin{array}{l}\text { Myeloproliferative syndrome } \\
\text { [37] }\end{array}$ \\
\hline $\begin{array}{l}\text { Case } \\
6\end{array}$ & 10q26(del:127 Mb-133Mb) & $46, X Y$, del(10)(q26.13) & / & $\begin{array}{l}\text { Chromosome } 10 q 26 \text { deletion } \\
\text { syndrome [38] }\end{array}$ \\
\hline $\begin{array}{l}\text { Case } \\
7\end{array}$ & 14q24.3-q32.33(del:44 Mb-105 Mb) & $46, \mathrm{XN}$,del(14) & / & Deafness [39] \\
\hline $\begin{array}{l}\text { Case } \\
8\end{array}$ & 15q11.2-q13(dup:24 Mb-31Mb) & $47, \mathrm{XN}, \mathrm{dup}(15)(\mathrm{q} 13)$ & / & NA \\
\hline $\begin{array}{l}\text { Case } \\
9\end{array}$ & 18q22.3-q23(del:72 Mb-77.98Mb) & $46, \mathrm{XN}$, del(18)mat & $46, \mathrm{XN}, \mathrm{del}(8)$ & NA \\
\hline $\begin{array}{l}\text { Case } \\
10\end{array}$ & 21q11(dup:15 Mb-16Mb) & $46, X Y$ & $\begin{array}{l}\text { 46,XN,dup (21q11.2)(15.4Mb- } \\
15.72 \mathrm{Mb}) \times 3\end{array}$ & NA \\
\hline $\begin{array}{l}\text { Case } \\
11\end{array}$ & 21q11.2-q21(dup:15 Mb-25Mb) & 47, XN,dup(21)(q21.2)mat & / & Usher syndrome [40] \\
\hline $\begin{array}{l}\text { Case } \\
12\end{array}$ & 22q11(dup:17.46Mb-21.52Mb) & $47, X Y, \operatorname{der}(22)$ & $\begin{array}{l}46, X N, \operatorname{dup}(22 \mathrm{q} 11.1- \\
\mathrm{q} 11.21)(17.42 \mathrm{Mb}-21.46 \mathrm{Mb}) \times 4\end{array}$ & $\begin{array}{l}\text { DiGeorge syndrome (DGS) } \\
\text { [41] }\end{array}$ \\
\hline $\begin{array}{l}\text { Case } \\
13\end{array}$ & $X_{Z}=-17.652 Y_{Z}=-0.782$ & $46, X$,del $(X)(q 21), 1 q h+$ & / & / \\
\hline
\end{tabular}

/ no data, $N A$ no relevant information

thus a negative correlation between read coverage and the GC content among the chromosomes.

Based on a previous study, sex chromosome aneuploidy was frequently suspected from NIPT. The false-positive rate for monosomy $\mathrm{X}$ was surprisingly high (91\%), and the prediction of other SCAs was more accurate [25]. In Tables 4 and 5, we showed the positive effects of chromosome size, maternal age, and gestational age. We found that the positive results effected from different chromosomes were significantly different, but we could not find statistical significance in chromosome size, maternal age, or gestational age (Table 4). In this study, we found two cases with Robertsonian translocations $(\operatorname{der}(14 ; 21))$. For the most common Robertsonian translocations (der(13;14) and der(14;21)), empirical risk data were summarized by Scriven et al. [26], with a risk of $0.4 \%$ for an unbalanced result at a second trimester prenatal diagnosis and an overall risk of miscarriage of approximately $15 \%$ in the case of der(13;14). For female carriers of der(14;21), the estimated risk of trisomy 21 at second-trimester prenatal diagnosis is $15 \%$, whereas for male carriers, this risk remains $<0.5 \%$, increasing miscarriage in couples $[13,15]$. Cytogenetically, Robertsonian translocation or centric fusion of two long arms of acrocentric chromosomes involving chromosome 21 are the most common structural chromosomal aberrations, which occur with an incidence of $\sim 1$ in 1000 in the general population [27]. Although it seems that the prevalence of these structural abnormalities in males and females is similar, a recent study found that women carrying Robertsonian translocations carry the abnormality to the fetus at a rate four times higher than men [27]. Therefore, we recommend that chromosomal karyotypes be detected for parents of such fetuses.

At the same time, we also analyzed the subchromosomal microdeletions and microduplications, finding 51 (0.63\%)

Table 4 The positive result effects from maternal age and gestational age

\begin{tabular}{|c|c|c|c|c|c|c|c|}
\hline & \multicolumn{2}{|c|}{ Trisomy } & \multicolumn{2}{|c|}{ CNV } & \multicolumn{2}{|c|}{ Total } & \multirow[t]{2}{*}{$P$} \\
\hline & $\overline{\mathrm{TP}}$ & FP & $\overline{\mathrm{TP}}$ & $\overline{F P}$ & $\mathrm{TP}$ & $\overline{F P}$ & \\
\hline \multicolumn{8}{|l|}{ Age } \\
\hline$\geq 35$ & 9 & 4 & 2 & 18 & 11 & 22 & \multirow[t]{2}{*}{$>0.05^{*}$} \\
\hline$<35$ & 7 & 8 & 11 & 4 & 18 & 12 & \\
\hline \multicolumn{8}{|l|}{ GA at NIPT (weeks) } \\
\hline First trimester(9-13 weeks) & 0 & 0 & 0 & 0 & 0 & 0 & \multirow[t]{3}{*}{ / } \\
\hline Second trimester(14-27 weeks) & 1 & 9 & 13 & 22 & 14 & 31 & \\
\hline Third trimester( $\geq 28$ weeks) & 0 & 1 & 0 & 0 & 0 & 1 & \\
\hline
\end{tabular}

/ no data

${ }^{*}$ Chi-square test in total sample 
Table 5 The positive result effects from chromosome size

\begin{tabular}{|c|c|c|c|c|c|}
\hline & Positive cases & True-positive cases & False-positive cases & Unverified & $p^{*}$ \\
\hline \multicolumn{6}{|l|}{ Trisomy } \\
\hline Trisomy 13 & 11 & 1 & 6 & 4 & \multirow[t]{3}{*}{0.05} \\
\hline Trisomy 18 & 7 & 3 & 2 & 2 & \\
\hline Trisomy 21 & 36 & 20 & 5 & 11 & \\
\hline \multicolumn{6}{|c|}{ Microdeletions and microduplications } \\
\hline$\geq 10 \mathrm{Mb}$ & 37 & 9 & 19 & 9 & \multirow[t]{2}{*}{$>0.05$} \\
\hline$<10 \mathrm{Mb}$ & 12 & 4 & 3 & 5 & \\
\hline
\end{tabular}

${ }^{*}$ Fisher exact probability method

positive cases but with 13 (36.11\%) true-positive cases. As we know, most subchromosomal microdeletions and microduplications occur randomly [23]. In addition, some subchromosomal microdeletions and microduplications had recurrent CNVs, such as $1 \mathrm{p} 36,3 \mathrm{q}, 11 \mathrm{q} 23$, and 22q11.2 deletion syndromes, with conserved breakpoints that were almost identical even in unrelated individuals [28-31]. In this study, we found 13 (36.11\%) true-positive cases for chromosomal microdeletions or microduplications that were validated by chromosome karyotype analysis and FISH. Among the 13 true-positive cases, 9 cases occurred because of genetic mutations, while 4 cases were inherited from parents. By querying the Online Mendelian Inheritance in Man (OMIM) database, 7 cases were identified as syndrome diseases, and 6 cases were pathogenicity unknown (Table 3). The advantages of using diagnostic testing must be balanced with the risk of losing a potential normal pregnancy due to the procedure itself. Broadening the scope of NIPT seems to be the ultimate goal for prenatal screening, thus reducing risks. A major concern is defining for which conditions screening should be offered. The most prevalent microdeletion is 22q11.2, which causes DGS. After Down's syndrome, DGS is the second most common chromosomal abnormality and cause of congenital heart disease [32]. Although early diagnosis of CNVs can help to avoid years of stress experienced by patients, early treatment can help to improve the symptoms, but CNVs have variable penetrance. In some cases, children with $\mathrm{CNVs}$ inherited from parents may have different phenotypes. Therefore, if the NIPT results were positive, validation tests might be considered, such as chromosome karyotype analysis, FISH, or chromosomal microarray analysis.

In this work, we demonstrated the feasibility of performing noninvasive prenatal detection of fetal chromosomal microdeletions and microduplications on a genome-wide level and at $3 \mathrm{Mb}$ resolution. When stratified by $\mathrm{CNV}$ size, NIPT identified eight samples with $\mathrm{CNVs}>10 \mathrm{Mb}$ and seven samples with CNVs $<10 \mathrm{Mb}$. Ai-Hua et al. developed a method to identify $71.8 \%$ of CNVs using 3.5 million reads, but the performance dropped to $41.2 \%$ when $\mathrm{CNVs}$ were below $5 \mathrm{Mb}$ [13]. Straver et al. reported the detection of large CNVs (over $20 \mathrm{Mb}$ ) with low sequencing depth (0.15-1.66x), which had limited clinical value [33]. Lo et al. reported $64.5 \%$ (20/31) accuracy when 4-6 million reads were used to analyze samples with 3 to $42 \mathrm{Mb}$ CNVs [34]. However, if CNVs were smaller than $6 \mathrm{Mb}$, only 5 in 13 cases were identified. Several studies have claimed benefits; however, we suggest that microdeletions have not demonstrated a sufficiently low false-positive rate to be deemed practical or ethically acceptable, especially considering their low PPV [35]. Because a positive NIPT result should be confirmed using diagnostic techniques and PPV was still lower for some microdeletions, diagnostic testing seems preferable when the goal is to maximize the detection of microdeletion or microduplication syndromes.

NIPT for subchromosomal microdeletions and microduplications was still in its infancy. Until now, no technology had thoroughly validated their tests to a statistically significant level because of the rare occurrence of these chromosomal abnormalities. Therefore, it was very important that the NIPT data must be studied carefully. To be more efficient, NIPT should use increased DNA concentrations or optimized bioinformatics algorithms in CNV to detect CNVs across the whole genome with a very low FPR, as well as high sensitivity and specificity on real-life samples.

\section{Conclusion}

In the present study, we examined 8141 single pregnancies undergoing NIPT. The results of this study indicated that the accuracy of NIPT for T21 detection was higher than that of other chromosome aneuploidies and chromosomal microdeletions/microduplications; it also indicated that the positive predictive value for chromosomal microdeletion/microduplications was still low. Therefore, it was very important to improve the specificity, accuracy, and sensitivity of NIPT technology on the detection of subchromosomal microduplications and microduplications. As noted above, the effect of NIPT may be more pronounced with accurate estimation of the fetal DNA concentration ratio at earlier gestational ages and optimization of the $\mathrm{CNV}$ bioinformatics algorithm.

\section{Abbreviations}

cfDNA: Cell-free DNA; cffDNA: Cell-free fetal DNA; CNVs: Copy number variations; CVS: Chorionic villus sampling; DGS: DiGeorge Syndrome; 
FISH: Fluorescence in situ hybridization; MMSs: Microdeletion and microduplication syndromes; NIPT: Noninvasive prenatal testing; OMIM: Online Mendelian Inheritance in Man; PHA: Phytohemagglutinin PPV: Positive predictive value; SCA: Sex chromosome aneuploidy

\section{Acknowledgements}

None.

\section{Funding}

National Key Research and Development Program of China (2016YFC1000700, 2016YFC1000703).

\section{Availability of data and materials}

The datasets used and/or analyzed during the current study are available from the corresponding author on reasonable request.

\section{Authors' contributions}

All authors have materially participated in the study and manuscript preparation. YY carried out all the molecular genetic analyses and participated in the design of the work; LW, JW, PZ, JF, and JS collected all clinical data and participated in conceiving the work; and $\mathrm{HH}$ designed the work and drafted and revised the manuscript. All authors have approved the final article.

\section{Ethics approva}

This study was approved by the Ethics Committee of Second Affiliated Hospital, Army Military Medical University, and written informed consent was obtained from the patients.

\section{Consent for publication}

The authors declare that they have no competing interests and the patients in this case report had provided their consent for publication.

\section{Competing interests}

The authors declare that they have no competing interests.

\section{Publisher's Note}

Springer Nature remains neutral with regard to jurisdictional claims in published maps and institutional affiliations.

\section{Received: 22 September 2018 Accepted: 26 February 2019}

Published online: 12 March 2019

\section{References}

1. Lo YM, Corbetta N, Chamberlain PF, Rai V, Sargent IL, Redman CW, Wainscoat JS. Presence of fetal DNA in maternal plasma and serum. Lancet. 1997;350(9076):485-7.

2. Filoche S, Lawton B, Beard A, Dowell A, Stone P. New screen on the block: non-invasive prenatal testing for fetal chromosomal abnormalities. J Prim Health Care. 2017:9(4):248-53.

3. Zhang H, Gao Y, Jiang F, Fu M, Yuan Y, Guo Y, Zhu Z, Lin M, Liu Q, Tian $Z$, et al. Non-invasive prenatal testing for trisomies 21, 18 and 13: clinical experience from 146,958 pregnancies. Ultrasound Obstet Gynecol. 2015;45(5):530-8.

4. McCullough RM, Almasri EA, Guan X, Geis JA, Hicks SC, Mazloom AR, Deciu C, Oeth P, Bombard AT, Paxton B, et al. Non-invasive prenatal chromosomal aneuploidy testing--clinical experience: 100,000 clinical samples. PLoS One. 2014;9(10):e109173.

5. Song $Y$, Huang $S$, Zhou $X$, Jiang $Y$, Oi O, Bian $X$, Zhang J, Yan Y, Cram DS, Liu J. Non-invasive prenatal testing for fetal aneuploidies in the first trimester of pregnancy. Ultrasound Obstet Gynecol. 2015;45(1):55-60.

6. Kagan $\mathrm{KO}$, Sonek J, Wagner $\mathrm{P}$, Hoopmann M. Principles of first trimester screening in the age of non-invasive prenatal diagnosis: screening for chromosomal abnormalities. Arch Gynecol Obstet. 2017;296(4):645-51.

7. Quezada MS, Gil MM, Francisco C, Orosz G, Nicolaides KH. Screening for trisomies 21, 18 and 13 by cell-free DNA analysis of maternal blood at 10-11 weeks' gestation and the combined test at 11-13 weeks. Ultrasound Obstet Gynecol. 2015:45(1):36-41.

8. Neofytou MC, Tsangaras K, Kypri E, Loizides C, loannides M, Achilleos A, Mina P, Keravnou A, Sismani C, Koumbaris G, et al. Targeted capture enrichment assay for non-invasive prenatal testing of large and small size sub-chromosomal deletions and duplications. PLoS One. 2017;12(2): e0171319.

9. Yaron Y, Jani J, Schmid M, Oepkes D. Current status of testing for microdeletion syndromes and rare autosomal trisomies using cell-free DNA technology. Obstet Gynecol. 2015;126(5):1095-9.

10. Grati FR, Molina Gomes D, Ferreira JC, Dupont C, Alesi V, Gouas L, HorelliKuitunen N, Choy KW, Garcia-Herrero S, de la Vega AG, et al. Prevalence of recurrent pathogenic microdeletions and microduplications in over 9500 pregnancies. Prenat Diagn. 2015;35(8):801-9.

11. Oskarsdottir S, Vujic M, Fasth A. Incidence and prevalence of the 22q11 deletion syndrome: a population-based study in Western Sweden. Arch Dis Child. 2004;89(2):148-51.

12. Kruszka P, Addissie YA, McGinn DE, Porras AR, Biggs E, Share M, Crowley TB, Chung BH, Mok GT, Mak CC, et al. 22q11.2 deletion syndrome in diverse populations. Am J Med Genet A. 2017:173(4):879-88.

13. Yin AH, Peng CF, Zhao X, Caughey BA, Yang JX, Liu J, Huang WW, Liu C, Luo DH, Liu HL, et al. Noninvasive detection of fetal subchromosomal abnormalities by semiconductor sequencing of maternal plasma DNA. Proc Natl Acad Sci U S A. 2015:112(47):14670-5.

14. Liao C, Yin AH, Peng CF, Fu F, Yang JX, Li R, Chen YY, Luo DH, Zhang YL, Ou YM, et al. Noninvasive prenatal diagnosis of common aneuploidies by semiconductor sequencing. Proc Natl Acad Sci U S A. 2014;111(20):7415-20.

15. Wapner RJ, Christa Lese M, Brynn L, Ballif BC, Eng CM, Zachary JM, Melissa S, Platt LD, Daniel S, Grobman WA. Chromosomal microarray versus karyotyping for prenatal diagnosis. Obstet Gynecol Surv. 2013;68(23):2175.

16. Vlatkovic IB, Hafner T, Miskovic B, Vicic A, Poljak B, Stipoljev F. Prenatal diagnosis of sex chromosome aneuploidies and disorders of sex development--a retrospective analysis of 11-year data. J Perinat Med. 2014:42(4):529-34.

17. Johansson LF, de Boer EN, de Weerd HA, van Dijk F, Elferink MG, SchuringBlom GH, Suijkerbuijk RF, Sinke RJ, Te Meerman GJ, Sijmons RH, et al. Novel algorithms for improved sensitivity in non-invasive prenatal testing. Sci Rep. 2017:7(1):1838.

18. Hu H, Liu H, Peng C, Deng T, Fu X, Chung C, Zhang E, Lu C, Zhang K, Liang Z, et al. Clinical experience of non-invasive prenatal chromosomal aneuploidy testing in 190,277 patient samples. Curr Mol Med. 2016;16(8):759-66.

19. Advani HV, Barrett AN, Evans Ml, Choolani M. Challenges in non-invasive prenatal screening for sub-chromosomal copy number variations using cellfree DNA. Prenat Diagn. 2017:37(11):1067-75.

20. Shaffer LG, Bejjani BA, Torchia B, Kirkpatrick S, Coppinger J, Ballif BC. The identification of microdeletion syndromes and other chromosome abnormalities: cytogenetic methods of the past, new technologies for the future. Am J Med Genet C Semin Med Genet. 2007;145C(4):335-45.

21. Lisa G. Shaffer, Bassem A. Bejjani, Beth Torchia, Susan Kirkpatrick, Justine Coppinger, Blake C. Ballif, (2007) The identification of microdeletion syndromes and other chromosome abnormalities: Cytogenetic methods of the past, new technologies for the future. American Journal of Medical Genetics Part C: Seminars in Medical Genetics 145C (4):335-345

22. Weise A, Mrasek K, Klein E, Mulatinho M, Llerena JC Jr, Hardekopf D, Pekova S, Bhatt S, Kosyakova N, Liehr T. Microdeletion and microduplication syndromes. J Histochem Cytochem. 2012;60(5):346-58.

23. Cheung SW, Patel A, Leung TY. Accurate description of DNA-based noninvasive prenatal screening. N Engl J Med. 2015;372(17):1675-7.

24. Norton ME, Jacobsson B, Swamy GK, Laurent LC, Ranzini AC, Brar H, Tomlinson MW, Pereira L, Spitz JL, Hollemon D. Cell-free DNA analysis for noninvasive examination of trisomy. N Engl J Med. 2015;372(17):1589-97.

25. Reiss RE, Discenza M, Foster J, Dobson L, Wilkins-Haug L. Sex chromosome aneuploidy detection by noninvasive prenatal testing: helpful or hazardous? Prenat Diagn. 2017;37(5):515-20.

26. Scriven PN, Flinter FA, Braude PR, Ogilvie CM. Robertsonian translocations-reproductive risks and indications for preimplantation genetic diagnosis. Hum Reprod. 2001;16(11):2267.

27. Keymolen K, Staessen C, Verpoest W, Michiels A, Bonduelle M, Haentjens P, Vanderelst J, Liebaers I. A proposal for reproductive counselling in carriers of Robertsonian translocations: 10 years of experience with preimplantation genetic diagnosis. Hum Reprod. 2009;24(9):2365-71.

28. Ichimiya $Y$, Wada $Y$, Kunishima S, Tsukamoto $K$, Kosaki $R$, Sago H, Ishiguro A Ito Y. 11q23 deletion syndrome (Jacobsen syndrome) with severe bleeding: a case report. J Med Case Rep. 2018;12(1):3.

29. Verheij E, Speleman L, Mink van der Molen AB, Thomeer H. Congenital respiratory tract disorders in 22q11.2 deletion syndrome. Int J Pediatr Otorhinolaryngol. 2018;104:1-4. 
30. Zhen Zhang, Jian Wang, Niu li, Ruen Yao, Ji Chen, (2018) Cutis laxa in a patient with 1 p36 deletion syndrome. The Journal of Dermatology 45(7): 871-873

31. Ramieri V, Tarani L, Costantino F, Basile E, Liberati N, Rinna C, Cascone P, Colloridi F. Microdeletion 3q syndrome. J Craniofac Surg. 2011;22(6):2124-8.

32. Mcdonald-Mcginn DM, Tonnesen MK, Laufer-Cahana A, Finucane B, Driscoll DA, Emanuel BS, Zackai EH. Phenotype of the 22q11.2 deletion in individuals identified through an affected relative: cast a wide FISHing net! Genetics in Medicine. 2001;3(1):23-9.

33. Straver R, Sistermans EA, Holstege H, Visser A, Oudejans CB, Reinders MJ. WISECONDOR: detection of fetal aberrations from shallow sequencing maternal plasma based on a within-sample comparison scheme. Nucleic Acids Res. 2014;42(5):1635-45.

34. Lo KK, Karampetsou E, Boustred C, Mckay F, Mason S, Hill M, Plagnol V, Chitty LS. Limited clinical utility of non-invasive prenatal testing for subchromosomal abnormalities. Am J Hum Genet. 2016;98(1):34-44.

35. Snyder MW, Simmons LE, Kitzman JO, Coe BP, Henson JM, Daza RM, Eichler EE, Shendure J, Gammill HS. Copy-number variation and false positive prenatal aneuploidy screening results. N Engl J Med. 2015;373(26):2583.

36. Finsterer J (2008) Leigh and Leigh-Like Syndrome in Children and Adults. Pediatric Neurology 39(4):223-235

37. Score J, Hidalgo-Curtis C, Jones AV, Winkelmann N, Skinner A, Ward D, Zoi K, Ernst T, Stegelmann F, Dohner K, Chase A, Cross NCP (2012) Inactivation of polycomb repressive complex 2 components in myeloproliferative and myelodysplastic/myeloproliferative neoplasms. Blood 119 (5):1208-1213

38. Lin S, Zhou Y, Fang Q, Wu J, Zhang Z, Ji Y, Luo Y (2016) Chromosome 10q26 deletion syndrome: Two new cases and a review of the literature. Molecular Medicine Reports 14 (6):5134-5140

39. Ruf RG (2003) A Gene Locus for Steroid-Resistant Nephrotic Syndrome with Deafness Maps to Chromosome 14q24.2. Journal of the American Society of Nephrology 14(6):1519-1522

40. Smith RJH, Berlin Cl, Hejtmancik JF, Keats BJB, Kimberling WJ, Lewis RA, Möller CG, Pelias MZ, Tranebjær L (1994) Clinical diagnosis of the Usher syndromes. American Journal of Medical Genetics 50(1):32-38

41. Kraus C, Vanicek T, Weidenauer A, Khanaqa T, Stamenkovic M, Lanzenberger R, Willeit M, Kasper S (2018) DiGeorge syndrome. Wiener klinische Wochenschrift 130 (7-8):283-287

Ready to submit your research? Choose BMC and benefit from:

- fast, convenient online submission

- thorough peer review by experienced researchers in your field

- rapid publication on acceptance

- support for research data, including large and complex data types

- gold Open Access which fosters wider collaboration and increased citations

- maximum visibility for your research: over $100 \mathrm{M}$ website views per year

At $\mathrm{BMC}$, research is always in progress.

Learn more biomedcentral.com/submissions 